Book Review

\title{
Higher Education Research on the Issue of Dropout
}

\author{
Zsolt Kristóf ${ }^{1}$
}

Recommended citation:

Kristof, Zs. (2019). Higher Education Research on the Issue of Dropout. Central European Journal of Educational Research, 1(1).

Book review on Pusztai, G., Szigeti, F. (eds.): Dropout and Persistence in Higher Education. Debrecen University Press, University of Debrecen, 2018.

Keywords: dropout, persistence, higher education

The work entitled Dropout and Persistence in Higher Education by Gabriella Pusztai and Fruzsina Szigeti (eds.) was published in November 2018 by the Debrecen University Press.

In our country the dropout rate in undergraduate education reaches up to $40 \%$. This data alone would be sufficient to reach the conclusion that we are dealing with a relevant issue. Even though there are numerous other reasons to support this claim, research on student dropout is rather scarce. This serious and tangible issue demands more studies to be carried out. The present book can be considered a work that comes to fill in this lacuna.

Thirty-two authors have contributed to the volume which is divided into three chapters and contains eighteen studies altogether. The first chapter entitled "Interpretations of the Concept of Dropout" contains five studies which focus primarily on theoretical approaches and clarification of definitions. The second chapter entitled "Protective Factors" contains six studies presenting interesting, not frequently discussed solutions for preventing dropout. The last chapter entitled "Territorial and Institutional Dropout" contains seven works which focus on concrete locations and well-defined institutional data.

The present review touches upon each article in the book. We present details, characteristics, and results which we personally consider interesting and thought-provoking.

The first study in the book deals with indicators which help in investigating the phenomenon of student dropout. The author points out that in some cases what seems to be dropout is in fact a conscious decision, or even part of the student's life strategy. Relying on the Higher Education Information System (HEIS) database the author proves the following:

- Dropout rates are higher among students enrolled in correspondence education. This is due to

the fact that in certain areas of full-time education prolonging the course of studies is more frequent.

- Dropout is most likely to occur in the first years of study.

- An increase in the number of passive semesters, as well as a slowdown in credit accumulation can be considered warning indicators.

The application of a warning system based on the data presented above would provide significant help to students experiencing learning difficulties to complete their studies.

The second study investigates different cases and possibilities of student status termination and draws a comparison between institutions in Hungary and Hungarian institutions of higher education abroad. Apart from Hungarian regulations, the research also targets higher education institutions

\footnotetext{
${ }^{1}$ University of Debrecen, Debrecen, Hungary; zsolt.kristof@gmail.com
} 
operating in the Transcarpathian area and Transylvania. The study concludes that the possible causes of student status termination are rather similar in the three countries investigated. Students can opt for student status termination in all three countries. Romania does the most for student persistence; consequently the chances for student dropout are the weakest in this country. Ukraine with its strict laws regulating student status is at the other extreme. If students cannot account for a one-month absence, their status is terminated. Hungary occupies a middle position. In this country poor academic achievement is not necessarily followed by student status termination.

The next study focuses on the role of certain factors in student dropout. Some of the factors discussed are family background, eventual previous education, career choices, work during studies, maintaining relationships, as well as health behaviour. The research is based on semi-structured interviews relying on the opinions of higher education dropouts or young people exposed to this risk. The results reveal that the parents' social or cultural status and the emotional and social relationships within the family do not have a significant effect. Significant external factors influencing career choice are labour market needs, family, school and geographical distance. Work during studies was characterized by incongruence between the type of work done and students' field of study. Consequently, work did not contribute to student persistence in higher education. Social relationships had a significant impact on educational trajectories, and the authors find a correlation between love relationships and dropout.

The aim of the fourth study was to account for the delayed graduation of students in teacher training education and the possible causes for student dropout. The qualitative analysis was based on semi-structured interviews. Results show that families do not play a direct role in student dropout but a rather indirect one. Experiences prior to higher education can play a significant role, say for example constrained decision-making; all the more so because ill-chosen institutions can have a negative influence on students' trajectory, eventually ending in dropout. However, the authors emphasise the fact that student dropout does not always mean a definitive end of higher education plans. Following dropout, students' expectations from themselves to earn a degree can revive.

The last study of the first chapter focuses on the career choice and further education of high school graduates in the Vojvodina region. This is a very topical issue since in the past decades there has been a significant decrease in the number of Hungarian students in Vojvodina. The authors present the results of two researches carried out in 2002 and a very recent study conducted in May 2018. This latter study involved 326 high school graduates from Vojvodina enrolled in Hungarian education. The research shows that $55 \%$ of this group wished to continue their studies and $76 \%$ wished to do this in Hungarian. Nevertheless, more than half of the high school graduates would not continue their studies in Serbia but in Vojvodina. The fact that the majority of the interviewees would continue their studies in their mother land was a significant conclusion of the research. Their decision is motivated by higher quality standards, Hungarian education and proximity.

In the sixth study Gabriella Pusztai points out that the Bologna Process did not cut high dropout rates. She emphasizes the fact that $40 \%$ of students enrolled in undergraduate education and $20 \%$ of MA students in Hungary leave higher education without earning a degree. This data makes it obvious that there is an urgent need to professionally address the problem of student dropout. The study is based on the "Effects of institutional integration on student achievement" (IESA) database, containing the data of 2017 students, and measures dropout risk on a nine-item scale. The most significant results are the following:

- Students who have previously interrupted their studies are more at risk of dropping out of their current studies.

- Students at more selective institutions, with stricter requirements strive harder to complete their studies successfully.

- The dropout rate tends to be lower among female students as compared to male students.

- Material well-being tempers rather than encourages students' commitment to earning a degree. 
- $\quad$ Strong and versatile relationships with teachers and parents reduce the risk of dropping out.

The next work presents instructive life stories with a positive outcome of students at a high risk of dropout. Besides investigating the idea of how far a springboard can be stretched before it would break the author analyses three enhancing factors, namely: attitude towards school, faith and college for advanced studies. Semi-structured interviews yielded the following results:

- The period prior to higher education was characterized by a mixture of ritualistic and rational elements. Following the admission to the college for advanced studies rational elements started to dominate.

- In helping each other and solving conflicts the interviewees were prompted by faith, which has also led to an increase in the strength of community and facilitated the acquisition of attitudes useful in the world of work.

- Earning a diploma was not considered the goal but rather a means facilitating the achievement of long-term objectives.

- The college for advanced studies helped students to discover their strengths and weaknesses, as well as resources for achieving their goals.

The eighth paper investigates the effects of civic engagement on dropout. Does it offer protection against dropout or does it increase its chances by taking away time from studying? 1792 students were involved in the quantitative research. No proof has been found that students who are more actively involved in society are more committed to their studies and are at a lower risk of dropout, however it hasn't been proved either that civic engagement has a negative effect on students' achievement. Data also shows that students with a better economic, cultural and social status are not more committed to completing their studies as compared to more disadvantaged students. The authors point out that a strong student-parent relationship is beneficial in avoiding dropout.

The next study investigates the connection between persistence and doing sport. The study is based on the database of the 2012 HERD research carried out by the Centre for Higher Education Research and Development (CHERD). The research involved 2619 individuals, students from higher education institutions in the Northern Great Plain region in Hungary and Partium region in Romania. The results have partially confirmed the models which provide the theoretical framework for the research, i.e. the development model, the zero-sum model and the student integration model. In line with previous research the results show that a higher extent of social integration can have negative effects and could compete with learning objectives. All this can diminish the importance of academic communities, the commitment to the institution, and eventually the chances for completing the studies. The authors suggest launching mentor programmes within which students facing similar challenges could share their problems with each other and could inspire each other.

Today no educational institution - whether in public education or higher education - can allow itself not to address those student views which are related to the activity within the institution. The next article presents and analyses such experiences of leaders from about thirty higher education institutions that could facilitate the successful completion of studies. Some of the solutions presented in the paper are the following:

- measuring competences of freshmen,

- remedial courses,

- operating a reporting system,

- identifying critical subjects and teachers,

- continuous information on students' rights and obligations,

- possibility of payment in instalments,

- mentoring and involving students in research and teaching activities,

- colleges for advanced studies.

Besides many good practices the article emphasizes that dropout cannot be entirely eliminated, however most of its causes could be eradicated. 
The eleventh study deals with the concept of Inclusive University. Following the 2003 Michigan decision, the concept of Inclusive Excellence formulated in the USA has strengthened its position. The idea of Inclusive University is presented based on the model of the University of Pécs. As starting points the authors outline the following parameters: equal access and participation, strategic indicators (diversity benchmark, critical minimum value), as well as institutional inclusion. On the other hand, the outputs are presented through the concepts of dropout and academic excellence.

In the next study Prof. Dr. István Polónyi investigates the features of students living in disadvantaged regions. The research is based on data from the 2010, 2013 and 2016 higher education entrance examinations. The investigation has targeted the twenty most disadvantaged micro-regions and districts. The study has revealed that in the period under scrutiny, the proportion of students coming from disadvantaged regions, as compared to the total number of students, is significantly smaller, except in the case of undivided training. In 2016, in undergraduate education the proportion of students from the most disadvantaged regions was the highest in the fields of agriculture, administration, police and military, as well as teacher training. At the same time, in undivided training most students from disadvantaged regions were to be found in the teacher training programme. It is noteworthy that in 2016 the proportion of students coming from the most disadvantaged micro-regions was the highest at the University of Debrecen.

The thirteenth study investigates dropout rates within different specializations at the University of Debrecen. The analysis is based on students' motivation for further education. The correlation between the type of decision for further education and the specialization does not lead to a direct conclusion as regards dropout rate. However, for the majority of specializations, more than half of the students enrolled do not complete their studies in due time. According to the authors the number one reason for student dropout was not fulfilling training requirements. The highest risk of dropout is characteristic of the following fields of study: informatics $(74.7 \%)$, medicine $(70.7 \%)$, as well as law and political science (59.3\%).

In his work, Prof. Dr. Mihály Fónai investigates the phenomenon of dropout at the University of Debrecen. A fundamental feature of dropout is pointed out in the introduction, namely that the reasons for dropout are multidimensional. This multidimensional approach characterizes the interpretive framework of the study. The research involving 1352 students at the University of Debrecen yielded the following results: parents' level of education and students' gender do not have a significant effect on dropout; however, the financial situation of the family and financial difficulties do. Contrary to other findings in the field, learning outcomes had a non-measurable impact on dropout. In spite of their achievements, students often dropped out due to other reasons. In the case of correspondence students work is a facilitating factor; however, for full time students it poses a threat with particularly high risk.

The next study focuses on the Faculty of Economics and Business at the University of Debrecen. The authors have investigated subjects which pose challenges in meeting the requirements and have analysed their features from the point of view of dropout. They point out that students' characteristics can also play a role in unsuccessful learning outcomes. Students who are postponers and students who generally try to avoid failures are more prone to dropout. The results of both spring and autumn semesters show that there are approximately thirty subjects in the case of which more than 10 per cent of the students do not meet the requirements. The authors suggest a rethinking of the requirements for these subjects, however, they also point out that dropout is a complex phenomenon influenced by many other factors; consequently, the success rate alone does not account for the process.

The sixteenth study focuses on teaching music. The authors set out to investigate the reasons for dropout in the institutions teaching music. In higher education arts is a field with a rather low 
dropout rate; consequently, the results of this study could be relevant for professionals in other fields of higher education as well. The qualitative research was based on interviews conducted with the heads of faculties of art and music. One of the reasons for dropout was the foreign language exam. Studies have also been interrupted due to not fulfilling study requirements. Work is a hindrance for studies; however, it leads to dropout less frequently. The authors conclude that dropout rates are lower in this field of study because students are more committed and are more certain to find a job.

The one before the last study focuses on students enrolled in the Sports and Recreation Management program within the Faculty of Economics and Business at the University of Debrecen. The results of the in-depth interview research show that high quality learning and sports are compatible until the end of primary school. According to students, poor outcomes result from the lack of time for studying. Interview respondents as well as their parents find it important to study after sports practice and to earn a degree. Research results show that doing sports at a lower level is compatible with studies and dropout becomes a threat at professional level.

The last study investigates dropout among disadvantaged students in higher education institutions in border regions. The authors try to identify the causes of a possible risk of dropping out. The research involved 1226 students from the University of Debrecen, the Debrecen Reformed Theological University, and the University of Nyíregyháza. Results show that there are no significant differences between the motivating factors for choosing a higher education institution in the case of disadvantaged students as compared to other students. Nonetheless, disadvantaged students are more motivated by their friends' choices. The odds ratio also shows that disadvantaged students were less likely to make an effort to take part in classes and to complete their studies. Consequently, institutions need to pay particular attention to these students.

As a conclusion we would warmly recommend to all teachers the book entitled Dropout and Persistence in Higher Education. It contains precious information, though-provoking theories and efficient solutions not only for researchers in the field but to all teachers in higher education or public education, who have to face the acute threat of dropout on a daily basis. 